\title{
Life Satisfaction and Stock Market Participation
}

\author{
Xiaohui Yang \\ Fairleigh Dickinson University \\ Enxi An \\ Old Dominion University \\ Bing Chen \\ Wenzhou-Kean University
}

\begin{abstract}
Prior literature finds mixed evidence on the relationship between life satisfaction and stock market participation. Using the broad U.S. household survey data from the Panel Study of Income Dynamics (PSID), we find that households with higher life satisfaction are less likely to invest in stocks. Our findings hold during both financial crisis and non-crisis periods and remain unaffected after conducting the robustness analysis to mitigate endogeneity concerns. Our findings enrich the literature that examines the effect of emotional factors on household financial behavior. Our study also highlights that life satisfaction is an important factor in understanding investing behavioral biases and thus helps explain stock market participation puzzle. ${ }^{1}$
\end{abstract}

Keywords: household, financial behavior, life satisfaction, stock market participation

\section{INTRODUCTION}

Stock market participation is an important household financial behavior that significantly impacts the current and future household consumption, which has a large influence on Gross Domestic Product (GDP). Prior literature documents that household investment in stocks is determined by many factors such as fixed participation costs, wealth, financial knowledge, expectations, and cognitive ability. For example, Van Rooij et al. (2011) find people with low financial literacy are less likely to invest in stocks. Grinblatt et al. (2011) document investors with high Intelligence Quotient (IQ) are prone to investing in stocks. Chen and Stafford (2016) find households with mortgage distress tend to exit the stock market.

Life satisfaction is a key part of subjective well-being and indicates how satisfied an individual is with his life. Recent studies demonstrate the impact of life satisfaction on stock market participation (e.g., Delis and Mylonidis 2015; Laakso 2010). However, they find mixed results. Specifically, Delis and Mylonidis (2015) suggest that households with higher life satisfaction in Dutch are less likely to invest in stocks. On the contrary, Laakso (2010) finds that life satisfaction has a positive association with stock market participation by using the Survey of Health, Ageing and Retirement in Europe (SHARE). In theory, there are two psychological models examining the association: the Affect Infusion Model (AIM) and the Mood Maintenance Hypothesis (MMH). Specifically, AIM suggests that higher life satisfaction leads to more 
risk-taking behaviors (e.g., Forgas 1995; Chou et al. 2007), but MMH argues the opposite (e.g., Isen and Patrick 1983; Isen 1987, 2000). Due to the contradicting theories and mixed empirical findings, the impact of life satisfaction on stock market participation is still an open question.

Our paper investigates this question by using the household survey data in the United States. As the US has the largest consumer market and the most developed stock market in the world, it offers a valuable opportunity to examine this question. Consistent with the prediction of $\mathrm{MMH}$, we find that households with higher life satisfaction are less likely to invest in stocks. This study makes three contributions to the literature. First, we use a broad sample in the United States to investigate the question. Delis and Mylonidis (2015) use a sample of Dutch households, and Laakso (2010) exploits a sample of households in European countries; different cross-country factors such as investor protection limit the conclusion we can draw from their findings. Second, this study contributes to the literature examining the effect of emotional factors on household financial behavior. Third, this paper highlights that life satisfaction is an important factor that leads investors not to invest in stocks and thus helps explain the stock market participation puzzle.

\section{MODEL AND DATA}

We obtain data from the Panel Study of Income Dynamics (PSID). Our life satisfaction measure is the "A3 Life Satisfaction" in PSID, which states "Please think about your life as a whole. How satisfied are you with it? Are you completely satisfied, very satisfied, somewhat satisfied, not very satisfied, or not at all satisfied?" The measure is available in years 2009, 2011, 2013, and 2015. We use the following logistic model for our analysis:

Prob $\left(\right.$ Brokerage_Account $\left._{i}\right)=\beta_{0}+\beta_{1}$ Life_Satisfaction $_{i}+\beta$ Control Variables $+\varepsilon_{i}$

Brokerage_Account is a dummy variable equal to one if the household has a brokerage account and zero otherwise. The variable of interest is Life_Satisfaction, which is a dummy variable equal to one if the survey respondent is completely satisfied with his life and zero otherwise ${ }^{2}$. We also include the following control variables. Head_Employment is equal to one if the household head is employed and zero otherwise; Wife_Employment is equal to one if the household wife is employed and zero otherwise; No_Wife is equal to one if there is not a wife in the household and zero otherwise; Lag_Income indicates the natural log of family income in last year; Household_Wealth is the natural log of household wealth without home equity at the time of survey; Mortgage_Distress is equal to one if the household has mortgage distress and zero otherwise. Male_Head is equal to one if the household head is a male and zero otherwise; Age1 is equal to one if the household head is younger than 35 and zero otherwise; Age2 (Age3) is equal to one of the household head is between 35 (50) and 49 (64) and zero otherwise; High_School is equal to one if household head's highest level of education is high school and zero otherwise. College is equal to one if household head's highest level of education is college and zero otherwise; Graduate is equal to one if household head's highest level of education is graduate degree or above and zero otherwise; African_American is equal to one if the household head is an African American and zero otherwise.

We run a pooled regression to examine the impact of life satisfaction on stock market participation. We also run regression (1) separately for observations in crisis period (year 2009) and non-crisis periods (years 2011, 2013, and 2015) to mitigate the impact of financial crisis on our analysis. To maintain reliability of the survey data in our sample, we only include households in which the survey respondent is either household head or wife. Households with non-positive family income or wealth are excluded.

\section{RESULTS AND DISCUSSION}

Table 1 describes the percentage of households that have stock accounts and the percentage of completely satisfied households among stockholders. A household is considered completely satisfied if the survey respondent is completely satisfied with his $l^{2} \mathrm{ife}^{3}$. In 2009, 22.54\% of the households have stock accounts. The percentage declines slightly to $18.02 \%, 17.47 \%$, and $17.08 \%$ in 2011,2013 , and 2015 
respectively. Among households with stock holdings, $17.81 \%$ are completely satisfied in 2009 . After the financial crisis, the percentage increases to $22.47 \%, 20.91 \%$, and $19.36 \%$ in 2011,2013 , and 2015 respectively.

TABLE 1

PERCENTAGE OF STOCKHOLDERS AND SATISFIED HOUSEHOLDS

\begin{tabular}{lcccc}
\hline & 2009 & 2011 & 2013 & 2015 \\
\hline Stockholders (\%) & 22.54 & 18.02 & 17.47 & 17.08 \\
Satisfied Households (\%) & 17.81 & 22.47 & 20.91 & 19.36 \\
\hline
\end{tabular}

Table 2 presents the regression results. Column (1) shows the results of the full sample. The coefficient on Life_Satisfaction is negative and significant at the $1 \%$ level (coef $=-0.269$; std error $=0.074$ ), suggesting life satisfaction has a negative effect on stock market participation. The estimated coefficient indicates completely satisfied households are $27 \%$ less likely to invest in stocks. Column (2) and (3) present the results for crisis periods (year 2009) and non-crisis periods (years 2011, 2013, and 2015). Consistently, we find the coefficients on Life_Satisfaction for crisis periods (coef $=-0.342$; std error $=0.115$ ) and non-crisis periods (coef $=-0.237$; std error $=0.096)$ are negative and significant at the $1 \%$ level. The estimated coefficients on control variables are consistent with expectation. For example, richer households are more likely to buy stocks, and families with mortgage distress are less likely to own stocks.

A potential endogeneity issue is that trading stocks could affect life satisfaction. To mitigate the endogeneity issue, we replace Life_Satisfication in regression (1) with Lag_Life_Satisfaction, i.e., Life_Satisfication in year t-2. Column (4) shows the results. Consistently, the estimated coefficient on Lag_Life_Satisfaction is negative and significant (coef $=-0.299$; std error $=0.072$ ), indicating life satisfaction is negatively associated with stock market participation.

TABLE 2

LIFE SATISFACTION AND STOCK MARKET PARTICIPATION

\begin{tabular}{lcccc}
\hline & \multicolumn{4}{c}{ Brokerage_Account } \\
\cline { 2 - 5 } & $2009-2015$ & 2009 & $2011-2015$ & $2011-2015$ \\
& $(1)$ & $(2)$ & $(3)$ & $(4)$ \\
\hline Intercept & $-11.204^{* * *}$ & $-10.351^{* * *}$ & $-11.839^{* * *}$ & $-11.816^{* * *}$ \\
Life_Satisfaction & $(0.577)$ & $(0.816)$ & $(0.216)$ & $(0.523)$ \\
& $-0.269^{* * *}$ & $-0.342^{* * *}$ & $-0.237^{* *}$ & \\
Lag_Life_Satisfaction & $(0.074)$ & $(0.115)$ & $(0.096)$ & \\
Head_Employment & & & & $-0.299^{* * *}$ \\
& & & & $(0.072)$ \\
Wife_Employment & $-0.234^{* * *}$ & -0.135 & $-0.279^{* * *}$ & $-0.276^{* * *}$ \\
& $(0.059)$ & $(0.120)$ & $(0.063)$ & $(0.080)$ \\
No_Wife & $0.092^{* *}$ & 0.162 & 0.063 & 0.067 \\
& $(0.041)$ & $(0.116)$ & $(0.045)$ & $(0.073)$ \\
Lag_Income & -0.024 & -0.006 & -0.010 & -0.016 \\
& $(0.104)$ & $(0.168)$ & $(0.152)$ & $(0.109)$ \\
& $0.180^{* * *}$ & $0.236^{* * *}$ & $0.177 * * *$ & $0.175^{* * *}$ \\
& $(0.047)$ & $(0.076)$ & $(0.059)$ & $(0.048)$ \\
\hline
\end{tabular}




\begin{tabular}{lcccc}
\hline Household_Wealth & $0.680^{* * *}$ & $0.603^{* * *}$ & $0.716^{* * *}$ & $0.718^{* * *}$ \\
Mortgage_Distress & $(0.447)$ & $(0.037)$ & $(0.045)$ & $(0.023)$ \\
Male_Head & $-0.300^{* * *}$ & $-0.378^{* *}$ & -0.285 & $-0.288^{* *}$ \\
& $(0.115)$ & $(0.176)$ & $(0.198)$ & $(0.130)$ \\
Age1 & $-0.375^{* * *}$ & $-0.419^{* *}$ & $-0.360^{* *}$ & $-0.359^{* * *}$ \\
& $(0.126)$ & $(0.170)$ & $(0.181)$ & $(0.113)$ \\
Age2 & $0.261^{* *}$ & -0.039 & $0.350^{* * *}$ & $0.331^{* * *}$ \\
& $(0.116)$ & $(0.162)$ & $(0.111)$ & $(0.106)$ \\
Age3 & $-0.131^{*}$ & $-0.427^{* * *}$ & $-0.065^{* *}$ & -0.074 \\
& $(0.074)$ & $(0.158)$ & $(0.032)$ & $(0.102)$ \\
High_School & $-0.276^{* * *}$ & $-0.428^{* * *}$ & $-0.253^{* * *}$ & $-0.263^{* * *}$ \\
& $(0.045)$ & $(0.142)$ & $(0.067)$ & $(0.087)$ \\
College & $0.422^{* * *}$ & $0.342^{*}$ & $0.493^{* * *}$ & $0.493^{* * *}$ \\
Graduate & $(0.068)$ & $(0.205)$ & $(0.062)$ & $(0.181)$ \\
& $0.970^{* * *}$ & $0.932^{* * *}$ & $1.045^{* * *}$ & $1.041^{* * *}$ \\
African_American & $(0.079)$ & $(0.197)$ & $(0.086)$ & $(0.174)$ \\
& $1.267^{* * *}$ & $1.200^{* * *}$ & $1.353^{* * *}$ & $1.353^{* * *}$ \\
\hline Number of observations & $(0.082)$ & $(0.215)$ & $(0.076)$ & $(0.182)$ \\
AIC (Intercept and & $-1.366^{* * *}$ & $-1.498^{* * *}$ & $-1.300^{* * *}$ & $-1.300^{* * *}$ \\
Covariates) & $(0.065)$ & $(0.212)$ & $(0.044)$ & $(0.147)$ \\
\hline Nins & 23,635 & 5,841 & 17,794 & 17,794 \\
& & & & $310,711.3$ \\
\hline
\end{tabular}

Numbers in parentheses are standard errors clustered by year.

$*, * *$, and ${ }^{* * *}$ denote the significant level of $10 \%, 5 \%$ and $1 \%$ respectively.

\section{CONCLUSION}

Using survey data from the PSID, this paper studies the impact of life satisfaction on stock market participation. We find that people with higher life satisfaction are less likely to invest in stocks. The findings hold both during financial crisis and non-crisis periods and remain unaffected in the robustness test. Future research can examine the channel through which life satisfaction influences household decisions on stock investments.

\section{ENDNOTES}

1. All the authors contribute to the paper equally. Corresponding author: Bing Chen, Wenzhou-Kean University, 88 Daxue Rd, Ouhai, Wenzhou, Zhejiang Province, China 32506. Email: bchen@kean.edu.

2. When we define Life Satisfation as a category variable equal to 5 if the survey respondent is completely satisfied with his life, 4 if he is very satisfied, 3 if he is somewhat satisfied, 2 if he is not very satisfied, and 1 if he is not at all satisfied, the results (untabulated) of regression (1) are consistent with our findings in table 2.

3. According to the survey data from the PSID, there is only one survey respondent from a household each year. 


\section{REFERENCES}

Chen, B., \& Stafford, F.P. (2016). Stock market participation: Family responses to housing consumption commitments. Journal of Money, Credit and Banking, 48(4), 635-659.

Chou, K.L., \& Chi, I. (1999). Determinants of life satisfaction in Hong Kong Chinese elderly: A longitudinal study. Aging \& Mental Health, 3(4), 328-335.

Chou, K.L., Lee, T., \& Ho, A.H. (2007). Does mood state change risk taking tendency in older adults? Psychology and Aging, 22(2), 310.

Delis, M.D., \& Mylonidis, N. (2015). Trust, happiness, and households' financial decisions. Journal of Financial Stability, 20, 82-92.

Forgas, J.P. (1995). Mood and judgment: The affect infusion model (AIM). Psychological Bulletin, $117(1), 39$.

Grinblatt, M., Keloharju, M., \& Linnainmaa, J. (2011). IQ and Stock Market Participation. The Journal of Finance, 66(6), 2121-2164.

Isen, A. (1984). Towards understanding the role of affect in cognition. In R.S. Wyer \& T.K. Srull (Eds.), Handbook of social cognition, 3, 179-236.

Isen, A.M. (2000). Positive affect and decision making. In Handbook of Emotions, edited by M. Lewis and J.M. Havieland, 2, 417-435.

Isen, A.M., \& Patrick, R. (1983). The effect of positive feelings on risk taking: When the chips are down. Organizational Behavior and Human Performance, 31(2), 194-202.

Khattab, N., \& Fenton, S. (2009). What makes young adults happy? Employment and non-work as determinants of life satisfaction. Sociology, 43(1), 11-26.

Laakso, E. (2010). Stock market participation and household characteristics in Europe.

Margolis, R., \& Myrskylä, M. (2013). Family, money, and health: Regional differences in the determinants of life satisfaction over the life course. Advances in Life Course Research, 18(2), $115-126$.

Palmore, E., \& Luikart, C. (1972). Health and Social Factors Related to Life Satisfaction. Journal of Health and Social Behavior, 13(1), 68-80.

Van Rooij, M., Lusardi, A., \& Alessie, R. (2011). Financial literacy and stock market participation. Journal of Financial Economics, 101(2), 449-472. 